\title{
O USO DO YOUTUBE COMO FERRAMENTA COMERCIAL: O CASO DO MAGAZINE LUIZA
}

\author{
Thalita Knupp de Almeida
}

Eduardo Picanço Cruz

\section{RESUMO}

Este artigo explora o site YouTube, fenômeno da internet deste início de milênio, e como ele pode ser utilizado como ferramenta de marketing. Par tal, o pano de fundo é o caso da empresa Magazine Luiza, varejista brasileira do ramo de eletroeletrônicos e móveis, que vêm utilizando o site de vídeos para divulgar seus produtos. No primeiro momento, será apresentado o marketing, descrevendo conceitos de autores consagrados, verificando suas aplicações no mercado e conhecendo o mix de marketing. A seguir, analisaremos um dos quatro P's de marketing, a Promoção. Veremos as principais formas de comunicação entre organização e público-alvo. No item seguinte, é aprofundado o estudo em mídia, focando nos principais meios de comunicação e na forma como eles podem interagir. Em seguida, descreve-se o que é YouTube, como ele foi criado, a questão dos direitos autorais e de que forma ele pode ser usado na divulgação das empresas. Por fim, aprofunda-se na empresa Magazine Luiza, sua história, suas características principais e sua estratégia de marketing, principalmente no que diz respeito ao uso do YouTube.

Palavras-chave: Marketing. Mídia. Internet. YouTube. Magazine Luiza.

\begin{abstract}
In this work we'll address the YouTube website, the Internet phenomenon of the beginning of this millennium, can be used as a marketing tool. We'll review the Magazine Luiza case, a Brazilian retailer of electronics and mobile, which has been using the site's videos to promote their products. In the first chapter, we'll study the marketing, addressing its history, describing concepts of recognized authors, checking their applications on the market and knowing the marketing-mix. In the second chapter, we'll review of the four "P's" of the marketing, the promotion, which will see the main forms of communication between organization and audience. In the third chapter, we'll deepen our study on media, focusing on the mainstream media and how they can interact. In fourth chapter, we'll see what YouTube is, how it was created, its characteristics, the issue of copyright and in what way it can be used in the dissemination of business. In the fifth and final chapter, we'll study the company Magazine Luiza, its history, its characteristics and its marketing strategy, especially with regard how is used the site YouTube.
\end{abstract}

Keywords: Marketing. Media. Internet. YouTube. Magazine Luiza. 


\section{INTRODUÇÃo}

Segundo Heráclito (aproximadamente século IV a.C.), nada permanece imóvel, mas tudo se move, tudo muda, tudo se transforma. A partir deste pensamento, constata-se que a inovação é uma constante na humanidade, que está sempre aprendendo, aperfeiçoando e criando novas formas de satisfazer suas necessidades.

Em marketing, criatividade e inovação são essenciais para atingir os objetivos propostos. Os profissionais buscam sempre surpreender seu público, seja através de peças criativas ou de meios inusitados.

Não restam dúvidas que a internet é uma das principais invenções do final do século XX, e sua disseminação no início desse século prova sua força. Há muitas formas de utilizá-la: para diversão, busca de informações, negócios ou publicidade.

O presente artigo trata o modo como um site de vídeos, no caso o YouTube, está sendo utilizado pela empresa Magazine Luiza na comunicação com seu público-alvo.

A medida que a concorrência aumenta diariamente, é preciso atingir o consumidor de todas as formas. Este estudo apresenta uma nova ferramenta de promoção, uma nova maneira das empresas levarem sua mensagem ao seu cliente, atual ou potencial.

0 YouTube, que hoje é visto por muitos apenas como um site de entretenimento, pode ser largamente utilizado pelas empresas na divulgação de seus produtos e sua marca. É importante que a propaganda esteja onde o cliente está. E hoje, pelo menos 11,5 milhões de brasileiros e 300 milhões de pessoas em todo o mundo passam mensalmente pelo YouTube (FUSCO, 2008), números que não podem ser ignorados pelas empresas e pelas agências de publicidade.

É essencial que Universidades, Centros de Pesquisa e futuros administradores e publicitários estejam atentos a essa nova mídia, seguindo o exemplo da empresa Magazine Luiza, que viu no site uma oportunidade e já está utilizando-o para promover seus produtos.

\section{MARKETING}

Hoje em dia, existem várias empresas com ótimos produtos, excelentes profissionais, capital de giro suficiente e estrutura de qualidade, mas sem sucesso.

Simplesmente os clientes não aparecem, não compram e a empresa não cresce. Isto acontece por vários motivos, mas um é bem claro: falta de habilidade de marketing. As empresas precisam se comunicar com as partes interessadas atuais e potenciais e com o público em geral, e isso se dá através do marketing.

O marketing não é nada simples, e muito menos acidental. Necessita ser planejado e analisado com muita precisão. As empresas sujeitas a maior risco são aquelas que não conseguem monitorar seus clientes e concorrentes com cuidado e aperfeiçoar sempre suas ofertas de valor.

Para discutir questões de marketing, é importante ter em mente alguns conceitos, a começar pelo próprio conceito de marketing. De uma maneira bem simples, Kotler e Keller (2006) afirmam que o marketing "supre necessidades lucrativamente". Segundo eles, marketing 
consiste na tomada de ações que provoquem a reação desejada de um público-alvo; o objetivo é provocar uma resposta comportamental da outra parte.

A definição de acordo com a American Marketing Association (AMA), atualizada em 2005, é a seguinte:

Marketing é uma função organizacional e um conjunto de processos que envolvem a criação, a comunicação e a entrega de valor para os clientes, bem como a administração do relacionamento com eles, de modo que beneficie a organização e seu público interessado.

Segundo Kotler e Keller (2006), o marketing na sociedade regula as relações econômicas de troca com funções de equilíbrio entre oferta e demanda, além de interferir no processo social através da influência das mídias e de todas as atividades mercadológicas.

De acordo com a definição de Lima et al (2007) promoção (ou comunicação) consiste em "atividades que visam comunicar os atributos e benefícios do produto e persuadir os clientesalvo a adquiri-lo e consumi-lo".

Os objetivos da promoção podem ser resumidos em (i) criar consciência, ao informar para o mercado as características do seu produto; (ii) formar imagens positivas, ao incutir nas pessoas avaliações positivas sobre sua marca; (iii) identificar possíveis clientes, ao descobrir seus nomes, formas de contato e possíveis necessidades de clientes potenciais; (iv) formar relações de canal, ao aumentar a cooperação entre membros do canal; e (v) fidelizar clientes, ao criar valor para os clientes, satisfazer seus desejos e necessidades e conquistar sua fidelidade.

A atividade de promoção pode combinar seis elementos diferentes para criar a estratégia geral de comunicação de marketing: propaganda, venda pessoal, promoção de vendas, publicidade, marketing direto e eventos e experiências.

\section{MIDIA}

O termo mídia designa, de forma genérica, todos os meios de comunicação, ou seja, os veículos que são utilizados para divulgação de conteúdos de publicidade e de propaganda.

Os meios de comunicação levam a mensagem publicitária do anunciante aos consumidores. Estes podem atingir enormes audiências, como as emissoras de televisão, ou serem dirigidos à apenas uma pessoa, como uma mala direta.

Segundo Daniel Okrent, editor de novas mídias da Time Inc. (apud Veronezzi, 2002), "os meios de comunicação não existem para contar às pessoas o que elas querem saber, mas para falarem aquilo que elas não sabem que desejam saber."

Para escolher o melhor meio de comunicação, é importante ter em mente que cada um tem uma audiência própria e serve para uma finalidade específica de mídia.

A internet vem crescendo rapidamente como meio de comunicação, mas sua participação no mercado publicitário ainda é tímida e até mesmo o formato mais eficaz de uso dessa mídia ainda não está definido.

Algumas das formas de propaganda na internet são:

a) Página Web - é o espaço da empresa na internet, constituído através do seu domínio. Pode 
vender o produto através da internet ou apenas divulgar informações sobre a empresa.

b) E-mail-marketing - é a utilização do e-mail como ferramenta de marketing direto. São mensagens de divulgação da empresa e de seu produto ou serviço enviadas ao consumidor através da autorização prévia do mesmo.

c) Banner publicitário - é algo parecido com um "outdoor" na internet, uma propaganda da empresa num site (preferencialmente de grande tráfego de usuários) que, ao ser clicado, direciona o usuário à página do anunciante.

d) Janela pop-up - consiste numa janela extra que abre no navegador ao visitar uma página web, contendo a informação de anunciante e um link que direciona para a página do mesmo. Hoje em dia, muitos navegadores bloqueiam esse tipo de propaganda, conhecida como "anúncio de interrupção".

e) Pesquisa de opinião pública - é uma enquete desenvolvida e inserida sempre na página principal do site desejado, seja ele de abrangência nacional, regional ou local. A configuração da enquete possibilita um maior controle da mesma (inclusive não permitindo que seja computado mais de um voto por usuário), acompanhamento diário dos resultados e indicação da enquete para amigos.

f) Mecanismos de busca - consiste no aprimoramento do site para que o mesmo tenha uma boa colocação nos sites de busca, como o Google.com. 0 ideal é que o link para o seu site esteja entre os primeiros resultados quando o usuário digita o nome do seu produto num site de busca.

g) Newsletter - diferente do e-mail marketing, o newsletter consiste num boletim digital com diagramação estilo jornal e com periodicidade diária, semanal, quinzenal ou mensal que são enviadas via e-mail. Também conhecido como MEPPS - Mensagem Eletrônica de Publicidade de Produtos e Serviços - é largamente utilizado na divulgação de notícias, suporte técnico, produtos e serviços. 0 envio de newsletter através de email está de acordo com as normas internacionais de marketing por email e anti-spam, e deverá conter opção de remoção do email do usuário que não mais deseje recebê-lo.

Veronezzi (2002) afirma que talvez a internet não seja um novo meio de comunicação, e sim a convergência de todos os meios, já que basta acessá-la para lermos jornais e revistas, ouvirmos rádio, assistirmos TV e filmes. Por outro lado, contrapõe o autor, a internet pode ser considerada algo totalmente novo por possuir algumas características não encontradas nos outros meios, como instantaneidade, megacapacidade de armazenagem, facilidade na busca de informações e direcionamento individual.

Sobre a propaganda na internet, Vaz (2008) afirma o seguinte:

Na internet, a propaganda dá lugar à publicidade, o marketing de interrupção dá lugar ao marketing de relacionamento e de permissão, a forma dá lugar ao conteúdo, a via de mão única dá lugar ao diálogo e à participação, o corporativo ao flexível e orgânico, a 'campanha', à idéia, o marketing de massa ao relacionamento com o indivíduo, os segredos da instituição, à transparência absoluta e a empresa cede lugar ao consumidor...

Na internet, a possibilidade de personalizar o marketing, e consequentemente, de atingir o consumidor, atual ou potencial, é muito maior. 
Segundo Bishop (2000), a promoção por meio da Internet é mais racional do que emocional, implicando num processo de persuasão e não apenas de informação, que pode variar, evidentemente, conforme o tipo de produto ou serviço.

Ainda segundo o autor, as ações promocionais na internet têm os seguintes objetivos: fornecer informações para consumidores e outros interessados, aumentar a procura, diferenciar um produto ou serviço, incrementar o valor de um produto ou serviço e estabilizar as vendas.

Para Limeira (2002) com a utilização do ferramental Internet, o composto promocional é afetado diretamente no âmbito do marketing direto. A Internet representa um canal adicional para obtenção de informações de produtos e serviços pelos consumidores, mas também para a elaboração de programas de relacionamentos e estratégias de marketing. Com a utilização da Internet, as vendas pessoais passam a ser efetuadas por meio de links interativos entre a empresa e o comprador, e se este assim o desejar, sem a intervenção de um vendedor.

\section{YOUTUBE}

Criado em fevereiro de 2005 por Chad Hurley, Steve Chen e Jawed Karim, o YouTube é um site americano que permite que seus usuários carreguem, assistam e compartilhem vídeos em formato digital.

Seu nome vem do inglês you - você e tube - tubo, ou, neste caso, gíria utilizada para designar a televisão. Em português, a tradução seria algo como "TV Você" ou "Você TV".

Figura 1: Logotipo do YouTube

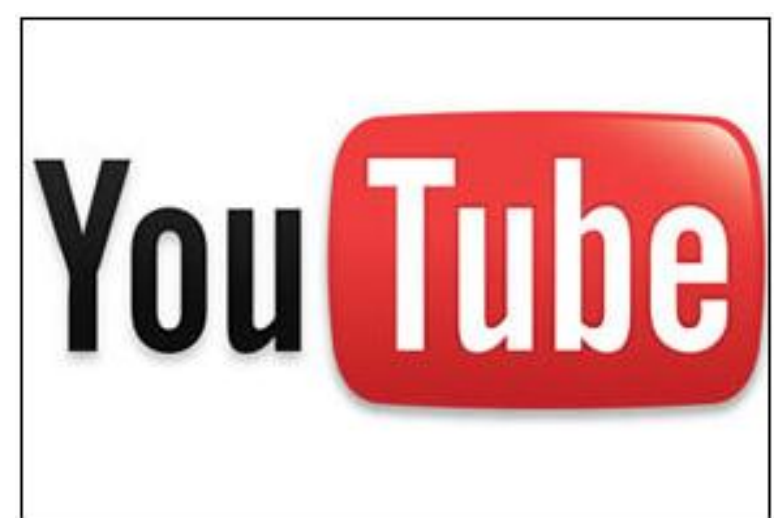

Fonte: br.youtube.com

O serviço é um dos principais ícones de uma tendência conhecida como Web 2.01, que também inclui o Wikipédia (enciclopédia colaborativa) e redes sociais como Orkut e MySpace. O YouTube leva ao extremo a idéia de colaboração on-line: os próprios internautas alimentam o site com vídeos que são assistidos por outros usuários da web.

Contribuíram para a rápida popularidade da página o famoso marketing "boca-a-boca", além da organização dos arquivos por categoria, a facilidade de acessar e enviar os vídeos e a exibição do conteúdo no formato streaming, que dispensa o download de arquivos. 0 serviço

\footnotetext{
1 Web 2.0 é um termo é utilizado para descrever a segunda geração da World Wide Web - tendência que reforça o conceito de troca de informações e colaboração dos internautas com sites e serviços virtuais. A ideia é que o ambiente on-line se torne mais dinâmico e que os usuários colaborem para a organização de conteúdo. (Folha On line, acessado em setembro de 2008),
} 
também oferece um código HTML (do inglês Hyper Text Markup Language), o que permite que o vídeo seja adicionado em blogs ou páginas pessoais.

O YouTube utiliza o formato Adobe Flash para disponibilizar o conteúdo. É o mais popular site do tipo devido à possibilidade de hospedar quaisquer vídeos (exceto materiais protegidos por copyright, apesar deste material ser encontrado em abundância no site).

O tamanho dos vídeos é limitado ao máximo de 10 minutos de duração. Essa restrição foi estabelecida em função do envio de episódios completos de séries da televisão e material com copyright enviados pelos usuários.

\section{FATOS IMPORTANTES}

A história do site teve início em 2005, numa garagem em San Francisco (Califórnia, EUA). Chad Hurley, Steve Chen e Jawed Karim, três jovens com menos de 30 anos, queriam criar uma forma fácil de compartilhar os vídeos que tinham gravado em uma reunião de amigos. "Estávamos em um jantar em janeiro de 2005, onde fizemos arquivos digitais. No dia seguinte, não conseguíamos enviá-los por email e demoramos muito para colocá-los na internet. Pensamos que deveria haver uma forma mais fácil de fazer isso", afirmou Hurley, em entrevista à revista Fortune. Os três amigos trabalharam juntos na PayPal, uma empresa de pagamento e transferência de dinheiro via internet comprada em 2002 pelo site de comércio eletrônico eBay. Por conta desta experiência profissional, eles conheceram Roelof Botha, executivo da PayPal e parceiro do fundo de investimento Sequoia Capital, que investiu US\$ 3,5 milhões no site de vídeos em novembro de 2005. Um mês depois, em dezembro de 2005, o site foi lançado oficialmente.

O site obteve sucesso rapidamente e em outubro de 2006, apenas 10 meses após do lançamento oficial da página na internet, o YouTube foi adquirido pela Google Inc. pela quantia de US\$1,65 bilhão em ações, tornando-se uma subsidiária independente da líder em serviços de pesquisa e publicidade on-line.

Buscando expandir o site para todo o planeta, a partir de junho de 2007 o YouTube apresentou-se em outros idiomas, como português, francês, italiano, japonês, entre outros, somando quinze idiomas oferecidos. Pouco depois, lançou sites locais em 19 locais geográficos.

Em dezembro de 2007, o YouTube teve quase 46 milhões de visitantes únicos apenas nos Estados Unidos (VAZ, 2008).

\section{YOUTUBE E MARKETING}

Alguns profissionais de marketing adotaram a plataforma de marketing do YouTube como um veículo inovador e atraente para conectar-se com seus públicosalvo e estão aumentando as vendas e a exposição de suas empresas e marcas de muitas formas diferentes. Em alguns casos, eles exibem publicidade em vídeo, mas também patrocinam concursos, criando canais de marca e acrescentando seu próprio conteúdo original ao site. Este modelo se encaixa naturalmente na filosofia do YouTube - a experiência do usuário em primeiro lugar.

Há muitas outras formas para usuários, parceiros e anunciantes se beneficiarem da relação com os milhões de pessoas que formam a maior comunidade de vídeos on-line do mundo, como o Programa de Parcerias e o YouTube Insight. 
Com o Programa de Parcerias do YouTube, os criadores de conteúdo original têm a oportunidade de gerarem receita com seus trabalhos e receberem os mesmos benefícios promocionais oferecidos a outros parceiros de conteúdo profissional do YouTube.

Já o YouTube Insight é uma ferramenta gratuita que permite à qualquer pessoa com uma conta do YouTube - usuários, parceiros ou anunciantes - visualizar estatísticas detalhadas sobre os vídeos enviados ao site, que lhes oferece um vislumbre sobre tendências de audiência em termos cronológicos e demográficos. Além de satisfazer a curiosidade sobre o poder de atração que a pessoa exerce no site, as ferramentas analíticas oferecem aos criadores de vídeo recursos (ainda rudimentares) para descobrir como gerar receita com a publicidade vendida ao lado dos vídeos.

"Não importa que o vídeo seja assistido por 10 pessoas ou por 10 milhões de pessoas, todo mundo quer sempre saber a mesma coisa. Quem está assistindo? De onde vêm os espectadores? Como eles encontraram meu vídeo?", afirmou o YouTube em seu blog.

\section{O CASO MAGAZINE LUIZA}

O Magazine Luiza S.A. é uma empresa brasileira de varejo de móveis e eletroeletrônicos, que iniciou suas atividades em 16 de novembro de 1957 na cidade de Franca, interior do estado de São Paulo. Segundo informações do seu site (www.magazineluiza.com.br), a empresa encerrou o ano de 2007 com o faturamento de R 2,6 bilhões. Seu crescimento anual foi de 18\% e o comércio eletrônico do Magazine Luiza apresentou um crescimento de 52\%.

Figura 2: Logotipo do Magazine Luiza

\section{magazineluiza}

Fonte: www.magazineluiza.com.br

O crescimento da rede ganhou mais impulso em 1992, quando a diretoria da empresa criou uma holding, e Luiza Helena Trajano, sobrinha dos fundadores, passou a ocupar o cargo de superintendente. Hoje, o Magazine Luiza possui 439 lojas (sendo 380 lojas convencionais e 59 virtuais) distribuídas por sete Estados brasileiros: São Paulo, Minas Gerais, Goiás, Mato Grosso do Sul, Paraná, Santa Catarina e Rio Grande do Sul. Para atender todas as lojas, o Magazine Luiza possui Centros de Distribuição em Ribeirão Preto (SP), Ibiporã (PR), Caxias do Sul (RS), Navegantes (SC), Contagem (MG) e Louveira (SP). Este último foi inaugurado em novembro de 2007, sendo um dos mais modernos centros de distribuição do Brasil, com mais de 50 mil metros quadrados de área de armazenagem. Situado à beira da Rodovia Bandeirantes, próximo a Jundiaí e São Paulo, o Centro de Distribuição Bandeirantes permite melhor eficiência logística e serve de base para o projeto de expansão da empresa, que incluí a ousada inauguração simultânea de 50 lojas na cidade de São Paulo, ocorrida em 22 de setembro de 2008 (na verdade, por atrasos nas obras, seis lojas não foram inauguradas nesse dia).

A empresa também apresenta outros números grandiosos: São 14 milhões de clientes cadastrados e quase 13 mil funcionários.

Seus principais concorrentes são a Casas Bahia e o Ponto Frio. E como fornecedores, podemos 
destacar a Consul, a Brastemp, a Arno e a Sony.

Além das lojas convencionais, a empresa utiliza outros canais de venda, que incluem as Lojas Virtuais, o Site e o Televendas, descritos abaixo segundo Saccol (2003).

As Lojas Virtuais apresentam um conceito inovador, no qual o Magazine Luiza foi pioneiro no Brasil. Nessas lojas não há produtos físicos; as vendas são realizadas em "células", compo stas de mesas com computadores no qual são demonstrados os produtos através de um catálogo eletrônico e realizadas todas as demais operações (cadastro do cliente, análise de crédito, etc.). Seu alvo são cidades pequenas, com cerca de 100.000 habitantes, ou bairros de grandes cidades. Seu custo é cerca de $15 \%$ do custo de uma loja tradicional e elas possuem em média $150 \mathrm{~m} 2$, enquanto uma loja convencional possui cerca de $800 \mathrm{~m} 2$. É parte do conceito das Lojas Virtuais a interação com a comunidade onde estão instaladas. Cada loja conta com uma espécie de "Centro de Eventos", no qual são oferecidos diversos cursos e encontros na comunidade, além de microcomputadores para uso e acesso gratuito à Internet. Nas Lojas Virtuais há também um posto bancário para recebimento de contas, atraindo e oferecendo serviços adicionais aos clientes.

O site do Magazine Luiza (magazineluiza.com.br) é a "loja" com o maior volume de vendas de toda a rede, sendo responsável por $15 \%$ do faturamento total da rede. Juntamente com o site comercial está o "Tia Luiza", um site com informações e dicas de uso dos produtos comercializados. 0 site tem aproximadamente 1,2 milhões de visitantes únicos por mês, segundo pesquisa da comScore de setembro de 2008.

0 Televendas serve basicamente para apoiar as vendas realizadas via internet. 0 setor, localizado em Franca, interior de São Paulo, conta com uma equipe própria de cerca de 20 pessoas. Entre as suas principais atividades estão a resolução de dúvidas dos clientes do site, respostas a e-mails, entre outras.

\section{MARKETING DO MAGAZINE LUIZA}

Segundo o site do Magazine Luiza, a Diretoria de Vendas e Marketing, liderada por Frederico Trajano, tem como premissa básica "Campanhas Agressivas, Inovadoras e Verdadeiras. Magazine Luiza: A empresa que fala e faz!". Essa diretoria é subdividida em vários departamentos, conforme veremos a seguir.

A função do Departamento de Marketing "é criar um planejamento de Campanha Promocional e de Marca para a empresa e promover seus produtos e sua marca para os consumidores". Ele é responsável pela área de pesquisas e estudos, patrocínios de projetos culturais/sociais e eventos, desenvolvimento de novas estratégias, campanhas publicitárias e planejamento e controle orçamentários. Os comerciais para televisão, spots de rádio, outdoors, anúncios de revistas e jornais, folders, tablóides, informativos e vídeos são produzidos pela sua agência de comunicação, a Ecto Ogilvy.

O Departamento Visual e de Merchandising é responsável pela formatação dos layouts e visual das lojas, de forma a dispor e destacar os produtos na loja para atrair a atenção dos clientes, bem como cuidar do bem-estar e do conforto dos clientes ao entrarem em um dos seus pontos-de-venda.

O Departamento de Marketing Promocional visa, por meio da integração entre o ponto-devenda e o consumidor, alcançar os objetivos estratégicos de divulgação da marca, vendas e fidelização de clientes, através da prospecção de novos clientes, endomarketing, parcerias 
com fornecedores para realização de ações promocionais, shows e eventos, e fortes ações promocionais de inauguração e reinauguração de lojas.

O Departamento de Marketing de Relacionamento tem como função principal fidelizar os clientes através do contato direto e personalizado. A empresa acredita que "um cliente verdadeiramente envolvido com a empresa não a abandonará por promoções eventuais do concorrente".

Além dessas áreas, a Diretoria de Vendas e Marketing comporta ainda os Departamentos de Ecommerce, de Serviços e de Vendas.

Segundo Luiza Helena Trajano Rodrigues, em entrevista concedida à José A. Souza (Diário de Franca) três dias antes da inauguração das 44 lojas do Magazine Luiza na capital paulista, o investimento na área de marketing em 2009 será de $\mathrm{R} \$ 60$ milhões, o que corresponde a um percentual 30\% superior se comparado à 2008.

A empresa investe bastante em ações promocionais, como podemos constatar no quadro abaixo:

Quadro 1 - Principais campanhas do Magazine Luiza

\begin{tabular}{|c|c|}
\hline Nome & O que é \\
\hline "Só amanhã" & $\begin{array}{l}\text { Venda de produtos específicos com preços muito abaixo dos praticados } \\
\text { no mercado durante um único dia, com divulgação no dia anterior. }\end{array}$ \\
\hline "Bota fora" & $\begin{array}{l}\text { Venda de produtos no site por um tempo pré-determinado com desconto } \\
\text { de até } 70 \% .\end{array}$ \\
\hline $\begin{array}{l}\text { "Liquidação } \\
\text { Fantástica" }\end{array}$ & $\begin{array}{l}\text { Venda de produtos nas lojas tradicionais com até } 70 \% \text { de desconto que } \\
\text { ocorre geralmente no primeiro sábado de todo ano. }\end{array}$ \\
\hline $\begin{array}{l}\text { "Liquidação da } \\
\text { Madrugada" }\end{array}$ & $\begin{array}{l}\text { Venda através do site, que é fechado antes da liquidação e reaberto de } \\
\qquad 00: 00 \mathrm{~h} \text { às } 08: 00 \mathrm{~h} \text { com descontos exclusivos. }\end{array}$ \\
\hline $\begin{array}{l}\text { "Caminhão do } \\
\text { Faustão" }\end{array}$ & $\begin{array}{c}\text { Promoção na qual a cada RS } 50,00 \text { em compras o cliente ganha um } \\
\text { cupom para participar. São realizados sorteios semanais no programa } \\
\text { Domingão do Faustão (Globo), e o premiado recebe dois caminhổes com } \\
\text { produtos do Magazine Luiza: um para ele próprio e outro para a pessoa } \\
\text { que este indicar. }\end{array}$ \\
\hline $\begin{array}{l}\text { "Transforme sua } \\
\text { casa" }\end{array}$ & $\begin{array}{c}\text { Promoção já finalizada na qual o cliente, ao comprar qualquer item da } \\
\text { linha de móveis, recebia uma carta para escrever porque deseja uma } \\
\text { transformação em algum cômodo de sua casa. } \\
\text { As cartas eram escolhidas pelo programa Domingo Legal do Gugu (SBT). }\end{array}$ \\
\hline $\begin{array}{l}\text { "Natal pra toda } \\
\text { Criança } \\
\text { Magazine Luiza" }\end{array}$ & $\begin{array}{c}\text { Ação natalina de cunho social onde parte das vendas do Magazine Luiza } \\
\text { é revertida para o UNICEF ("Natal Social"). }\end{array}$ \\
\hline "Vem ser feliz" & $\begin{array}{c}\text { A campanha de reposicionamento lançada em } 2005 \text {, que é o slogan da } \\
\text { empresa até hoje, reflete os valores e a filosofia da empresa. }\end{array}$ \\
\hline
\end{tabular}

Fonte: Site Magazine Luiza (www.magazineluiza.com.br)

\section{MAGAZINE LUIZA NO YOUTUBE}

Em dezembro de 2007 o Magazine Luiza fechou a primeira parceria de uma empresa de comércio eletrônico com o YouTube para divulgar vídeos sobre os produtos à venda. 0 acordo permitiu à Magazine Luiza criar um canal específico para seus vídeos dentro do site, com conteúdo e acesso controlados pela própria empresa. Produzidos pela agência de propaganda que possui a conta do Magazine Luiza, a Etco Ogilvy, e por uma equipe de 40 pessoas ligadas à gerência de multimídia da empresa, os filmes apresentam em cerca de um minuto as principais características de um determinado item disponível nas prateleiras das lojas ou no 
site da companhia.

Figura 3: Canal do Magazine Luiza no YouTube

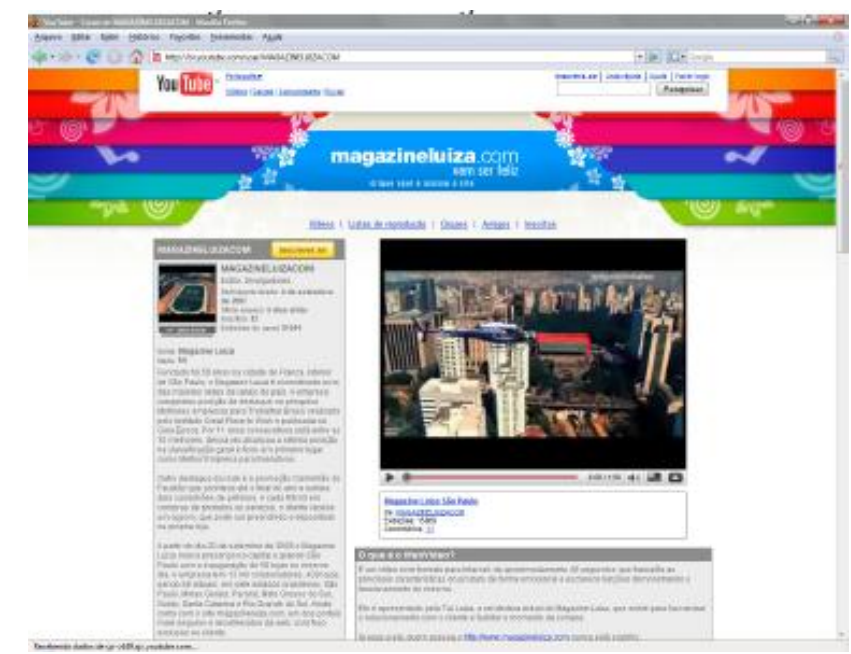

Fonte: br.youtube.com/user/MAGAZINELUIZACOM

Segundo reportagem de Peri de Castro para a revista Exame (2007), o vínculo entre as duas empresas surgiu em setembro de 2007, quando a rede varejista passou a alocar 2,1 milhões de reais, o equivalente a $15 \%$ da verba destinada a publicidade online, em links patrocinados de sites de busca, inclusive da Google. Os resultados do investimento em meio eletrônico foram tão rápidos, na avaliação da empresa, que em 2008 a empresa aumentou o orçamento em propaganda pela internet em $50 \%$. A mídia passou a receber $15 \%$ do total investido em publicidade, o que corresponde a 100 milhões de reais, e destinou metade desta fatia - cerca de sete milhões de reais - aos links patrocinados. 0 orçamento para investimento na produção dos vídeos para o YouTube em 2008 foi em torno de 1,5 milhões de reais. Cabe ressaltar que a varejista divide esses custos com os fabricantes dos produtos anunciados.

O acordo não representa uma fonte de renda imediata para a Google, proprietária do YouTube, uma vez que o Magazine Luiza não pagará pelo uso do site como plataforma para seus vídeos. Porém, mesmo sem observar aumento da receita direta por meio da parceria, o diretor-geral do Google no Brasil, Alexandre Hohagen, afirmou em entrevista ao jornalista Peri de Castro (2007) que a parceria representa um passo importante para a empresa, tanto por alargar a base de usuários do YouTube, uma vez que os clientes do Magazine Luiza passarão a visitar o site de vídeos, quanto por servir de vitrine para uma experiência que pode vir a ser lucrativa para a Google. A companhia também tende a ganhar com o aumento no número de links patrocinados, por parte dos parceiros que exibirem vídeos.

Para o Magazine Luiza, por sua vez, a possibilidade de exibir vídeos sobre os produtos serve como estratégia para aumentar a taxa de conversão do site, isto é, o volume de clientes que acabam comprando produtos, após acessar a página.

A empresa busca aumentar significativamente o número de compras online, e o uso dos vídeos é uma ferramenta chave nesse processo. Com eles, o Magazine Luiza busca ampliar a experiência de compra do usuário, já que os vídeos mostram como o produto é utilizado, e detalha as características do mesmo. Outro objetivo da empresa é 'viralizar' os vídeos, isto é, incentivar os internautas à indicar os vídeos entre seus contatos, e com isso, aumentar a audiência dos mesmos. 
Além disso, a parceria com o Google foi fundamental para a empresa pôr em prática o seu projeto multimídia, uma vez que para atrair os internautas é fundamental que os vídeos abram rapidamente, o que fica mais fácil quando eles estão numa plataforma como o YouTube.

No YouTube, o Magazine Luiza utiliza o webvideo, que é definido no próprio site como um "vídeo com formato para internet, de aproximadamente 40 segundos que transpõe as principais características do produto de forma emocional e esclarece funções demonstrando o funcionamento do mesmo. Ele é apresentado pela Tia Luiza, a vendedora virtual do Magazine Luiza, que existe para humanizar o relacionamento com o cliente e facilitar o momento da compra."

Figura 4: Vendedora virtual Tia Luiza

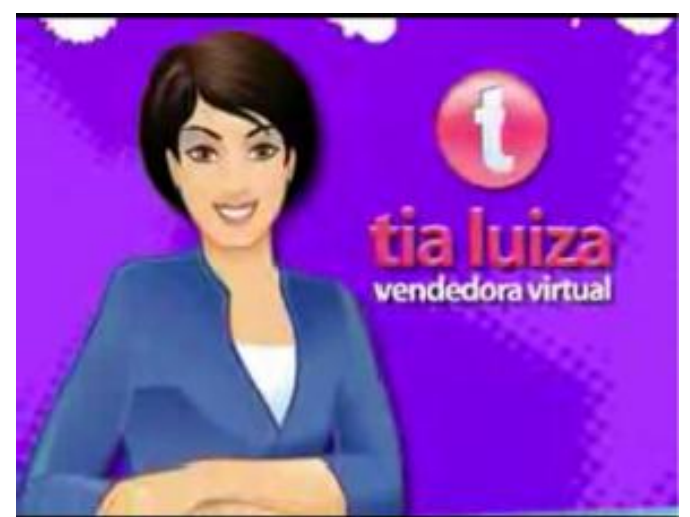

Fonte: br.youtube.com/user/MAGAZINELUIZACOM

Os vídeos de divulgação de produtos têm um formato padrão. Eles começam com uma abertura de dez segundos, no qual a vendedora virtual diz: "Bem vindo ao Magazine Luiza!". Em seguida, são apresentadas características do produto, tais como tamanho, formato, modo de usar, compatibilidades, diferenciais, entre outras. A empresa optou por não divulgar nos vídeos o preço, os prazos de pagamento, entre outras informações, já que essas são variáveis, sujeitas à aumentos, descontos e promoções.

Para alguns produtos, já no vídeo é oferecida a "garantiaplus" do Magazine Luiza, serviço de proteção ao produto adquirido pelo cliente que agrega um ano a mais de garantia, além daquela originalmente concedida pelo fabricante.

O vídeo termina com a vendedora virtual dizendo: “Aproveite, compre logo o seu!", sendo incluído o site da empresa no rodapé da tela.

Em outubro de 2008, todos os vídeos somavam mais de 580 mil exibições, estando em 6oㅜ lugar entre na categoria Patrocinadores do YouTube.

Havia 132 vídeos adicionados, que mostram as características e funcionalidades de diversos brinquedos, televisores, refrigeradores, móveis, entre outros, além de propagandas institucionais.

Com o objetivo de melhorar a análise, classificamos os vídeos em dez categorias: Beleza e Saúde, Brinquedos, Cine e Foto, Eletrodomésticos, Eletrônicos, Eletroportáteis e UD, Informática, Institucional, Móveis e Telefonia. O critério utilizado na classificação foi a categoria do produto no site do Magazine Luiza. Os produtos pertencentes a categorias com 
menos de quatro vídeos foram realocados em outras similares.

No gráfico da página seguinte vemos a distribuição dos vídeos por categoria:

Gráfico 1: Número de vídeos por categoria

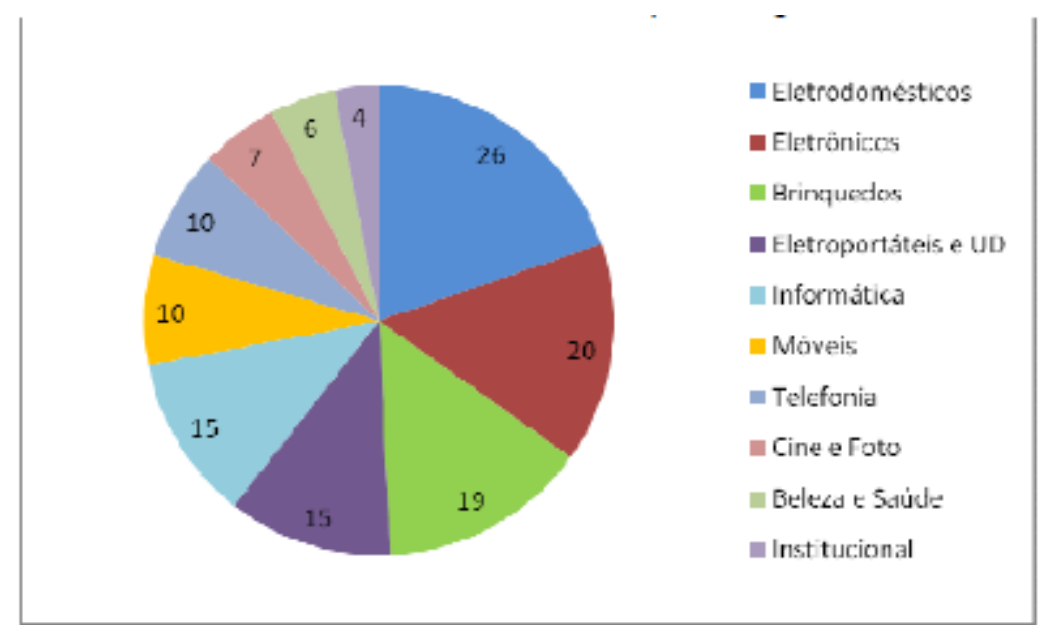

Fonte: Desenvolvimento próprio

Podemos observar que apenas três categorias, Eletrodomésticos, Eletrônicos e Brinquedos, são responsáveis por quase metade do total de vídeos postados.

Em 26 de outubro de 2008 observamos a audiência dos vídeos no YouTube. Os mais vistos eram da categoria Brinquedos, cujos vídeos têm grande apelo junto ao público infantil, já que mostram crianças se divertindo com os produtos.

O primeiro colocado, com mais de 100.000 exibições, era um vídeo sobre a Barbie Fada do Arco-Íris, fabricada pela Mattel:

Quadro 2 - Os dez vídeos mais vistos

\begin{tabular}{|clll|}
\hline Posiräo & Nome & Categoria & Exibicöes \\
\hline $1^{\circ}$ & Boneca Barbie Fada do Arco-lris & Brinquedos & 109.707 \\
\hline $2^{\circ}$ & CD Car MP3 HBD & Eletrónicos & 22.177 \\
\hline $3^{\circ}$ & Autorama Hot Wheels & Brinquedos & 19.255 \\
\hline $4^{\circ}$ & DVD Player com Display LCD & Eletrónicos & 18.605 \\
\hline $5^{\circ}$ & Faustão Dia das Mäes & Institucional & 17.734 \\
\hline $6^{\circ}$ & Magazine Luiza São Paulo & Institucional & 16.241 \\
\hline $7^{\circ}$ & MP3 e Jogos On-line da Barbie Real & Brinquedos & 15.970 \\
\hline $8^{\circ}$ & Guarda-Roupa Imperial & Móveis & 14.748 \\
\hline $9^{\circ}$ & Boneco Elmo & Brinquedos & 12.835 \\
\hline $10^{\circ}$ & Boneca Xuxinha & Brinquedos & 12.207 \\
\hline
\end{tabular}

Fonte: br.youtube.com/user/MAGAZINELUIZACOM (em 26 out. 2008)

Chama a atenção o significativo número de acessos aos vídeos institucionais, que são propagandas do Magazine Luiza também vinculadas na televisão. Isso mostra que o fortalecimento da marca também pode ser uma conseqüência do uso do YouTube como plataforma de divulgação.

No gráfico da abaixo podemos verificar a participação de cada categoria no total de exibições. 
Gráfico 2: Porcentagem de exibições por categoria
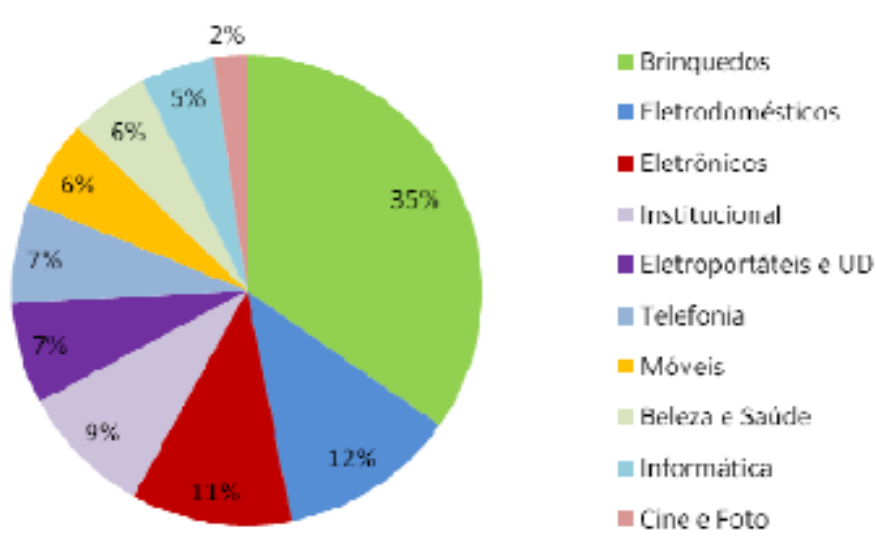

Fonte: Desenvolvimento próprio

Comparando os gráficos de número de vídeos com o de porcentagem de exibições por categoria podemos observar que os vídeos de Brinquedos, embora representem aproximadamente $15 \%$ do total de vídeos, são responsáveis por 35\% da audiência.

\section{CONCLUSÃO}

Estar atento às transformações do novo mundo em que vivemos é essencial para o sucesso de qualquer empresa. Nesse mundo competitivo e altamente integrado, independente da função, cargo, área, ramo de atividade, etc, temos que conhecer nossos clientes, e saber o que, quando, quanto e como eles querem receber nossas propostas de valor.

Conforme vimos neste artigo, uma nova ferramenta de comunicação está sendo lançada. Embora ainda seja um fenômeno recente, o YouTube já é grande, e ainda tem potencial de crescimento. As empresas que estiverem atentas a isso e o utilizarem de forma eficiente podem crescer junto com ele.

Estudamos o caso do Magazine Luiza, a primeira empresa brasileira a realizar uma parceria comercial com o YouTube para divulgar seus produtos. Este é um dos primeiros estudos realizados a respeito do YouTube, com certeza também é pioneiro com a utilização do caso Magazine Luiza. Sabemos que o pioneirismo tem seu custo, e no caso desse trabalho, o custo foi a falta de informações. Como essa parceria ocorreu a menos de um ano, a ausência de dados concretos sobre os resultados da utilização do site pela empresa foi um empecilho para a conclusão deste trabalho. Embora tivéssemos tentado contato com a empresa diversas vezes, não obtivemos resultados satisfatórios.

Isto porém não pode descartar a validade do estudo, já que a análise da estratégia de promoção do Magazine Luiza já é por si só um avanço na literatura rasa que hoje temos sobre o tema.

Podemos concluir que, independentemente de resultados financeiros, a marca Magazine Luiza está sendo fortalecida com esta parceria. Quando o acordo foi feito, o tema foi bastante explorado pela mídia, o que deixou a empresa sob fortes holofotes no final do ano passado (2007). Além disso, os vídeos têm atingido uma boa audiência, que tende a crescer a cada dia.

Fato curioso é com relação aos vídeos mais assistidos: os de brinquedos. 0 Magazine Luiza, que não é uma empresa desse ramo, está indiretamente atingindo o público infanto-juvenil, o 
que é ótimo para perspectivas futuras de crescimento da empresa. As crianças e os adolescentes, que estão cada vez mais cedo envolvidos com novas tecnologias, são os "consumidores de amanhã", e estabelecer laços com esse público é muito importante.

Como observação final, podemos dizer que ainda há muito terreno a ser explorado pelas empresas e posteriormente estudado pelos pesquisadores, pois cremos que o uso do YouTube pelas empresas está só começando.

\section{REFERÊNCIAS BIBLIOGRÁFICAS}

CASTRO, Peri de. Magazine Luiza lança vídeos de seus produtos no YouTube. Portal Exame, 2007. Disponível em: <http://portalexame.abril.com.br>. Acesso em: 04 ago. 2008.

DIZARD, Wilson P. Jr.; JORGE, Edmond; QUEIROGA, Tony. A nova mídia: a comunicação de massa na era da informação. Jorge Zahar Editor Ltda, 1998. Disponível em < http://books.google.com.br/books?id=gSXqISAN4FAC>. Acesso em 25 out. 2008.

FOLHA ON-LINE. Entenda o que é a Web 2.0. Folha de São Paulo, São Paulo, 10 junho 2006. Disponível em: <http://www.folha.uol.com.br >. Acesso em: 5 out. 2008.

FUSCO, Camila. A verdadeira TV digital. Exame. São Paulo, ano 42, no 21, 05 nov. 2008.

G00GLE ainda estuda fórmula para ganhar dinheiro com o YouTube. G1, São Paulo, 09 jun. 2008. Disponível em < http://g1.globo.com>. Acesso em 25 out. 2008.

IBGE. PNAD - Pesquisa Nacional por Amostra de Domicílios, 2007. Disponível em $<$ www.ibge.gov.br/estadosat/temas.php?sigla=mg\&tema=pnad_2007>. Acesso em 25 out. 2008.

JUSTIÇA manda tirar YouTube do ar. AdNews, São Paulo, 04 jan. 2007. Disponível em <http://www.adnewstv.com.br>. Acesso em 04 ago. 2008.

LAS CASAS, Alexandre Luzzi. Marketing: Conceitos, exercícios e casos. São Paulo: Atlas, 1997.

LAS CASAS, Alexandre Luzzi. Administração de Marketing: Conceitos, planejamento e aplicações à realidade brasileira. São Paulo: Atlas, 2006.

LIMA, Miguel, et al. Gestão de Marketing. Rio de Janeiro: FGV Editora, 2007.

KOTLER, Philip; KELLER, Kevin Lane. Tradução Mônica Rosenberg, Brasil Ramos Fernandes, Cláudia Freire. Administração de Marketing. São Paulo: Pearson Prentice Hall, 2006.

MACHADO NETO, Alfredo José, et al. Canais alternativos de distribuição: As "lojas virtuais" do Magazine Luiza. São Paulo, 2004. Disponível em <http://www.facef.br/facefpesquisa/2004/nr1/5_MACHADO_NETO_DONZELLI_DEPRETTO_ MERLO.pdf>. Acesso em 25 out. 2008.

MAGAZINE LUIZA. Canal no $\quad$ YouTube. Disponível em <http://br.youtube.com/user/MAGAZINELUIZACOM>. Acesso em 25 out. 2008.

MAGAZINE LUIZA. Site da empresa. Disponível em <http://www.magazineluiza.com.br>. Acesso em 25 out. 2008.

NÚMERO de pessoas que acessam a internet ultrapassa 800 milhões no mundo. IDG Now!, 
São Paulo, 18 mar. 2008. Disponível em <http://idgnow.uol.com.br>. Acesso em 04 ago. 2008. PEPPERS, Don; ROGERS, Martha. Marketing 1 to 1. São Paulo, 2004. Disponível em < http://www.1to1.com.br>. Acesso em 25 out. 2008.

PERFIL da Companhia. Google. Disponível em < http://www.google.com.br/intl/ptBR/profile.html >. Acesso em 04 ago. 2008.

POLONI, Gustavo; SALOMÃO, Alexa. A batalha do varejo. Época Negócios. São Paulo, ano 2, no 19 , set. 2008.

PROJETO INTER-MEIOS. Relatório de Investimentos. Agosto de 2008. Disponível em < http://www.projetointermeios.com.br/controller.asp\#>. Acesso em 25 out. 2008.

PROPAGANDA WEB. Disponível em < http://www.ideia.com.br/propaganda.htm>. Acesso em 25 out. 2008.

RIBEIRO, Lilian Soares P. de Souza. Mídia \& Pesquisa. Apostila para treinamento de funcionários. Infoglobo Comunicações S.A., 2005.

SACCOL, Amarolinda I. Costa Zanela. Alinhamento Estratégico da Utilização da Internet e do Comércio Eletrônico: Os Casos Magazine Luiza e Fleury. 2003. <www.anpad.org.br/rac/vol_09/dwn/rac-v9-n2-azs.pdf>. Acesso em 25 out. 2008.

SANT'ANNA, Armando. Propaganda: Teoria, técnica e prática. Thomson Learning Edições: São Paulo, 1998.

SOUZA, José A. Magazine Luiza - a caminho da liderança no varejo. Diário de Franca, São Paulo, 19 set. 2008. Disponível em <http://www.diariodafranca.com.br>. Acesso em 21 out. 2008.

STRAUBHAAR, Joseph D. Comunicação, Mídia e Tecnologia. Cengage Learning Editores, 2004. Disponível em < http://books.google.com/books?id=dUewZduJHIE > . Acesso em 25 out. 2008.

TOLEDO, Luciano Augusto; GOZZI, Sérgio; FEDICHINA, Márcio. 0 composto de marketing sob a ótica da internet. Revista Administração em Diálogo: São Paulo, 2004.

VAZ, Conrado Adolpho. Google Marketing: O Guia definitivo de marketing digital. São Paulo: Novatec Editora, 2008.

VERGARA, Sylvia Constant. Projetos e Relatórios de Pesquisa em Administração. São Paulo: Atlas, 2001.

VERONEZZI, José Carlos. Mídia de A a Z. São Paulo: Fligth Editora, 2002.

YOUTUBE Blog Brasil. Disponível em <http://br.youtube.com/blog>. Acesso em 01 nov. 2008.

YOUTUBE. Disponível em <http://pt.wikipedia.org/wiki/YouTube>. Acesso em 04 ago. 2008.

YOUTUBE começa invasão comercial no Brasil. AdNews, São Paulo, 05 dez. 2008. Disponível em <http://www.adnewstv.com.br>. Acesso em 04 ago. 2008.

YOUTUBE completa dois anos. AdNews, São Paulo, 14 fev. 2007. Disponível em 
<http://www.adnewstv.com.br>. Acesso em 04 ago. 2008.

YOUTUBE lança versão brasileira. AdNews, São Paulo, 19 jun. 2007. Disponível em <http://www.adnewstv.com.br>. Acesso em 04 ago. 2008.

YOUTUBE pagará a usuários que postarem vídeos mais vistos. AdNews, São Paulo, 31 jul. 2008. Disponível em <http://www.adnewstv.com.br>. Acesso em 04 ago. 2008. 